\title{
Amphiphilic Block Copolymers of Ethylene Oxide and 2 Methacryloyloxyethyl Ferrocenecarboxylate: Self-Assembly Behavior, Thermal and Electrochemical Properties
}

\author{
Margarita Droulia, Vasiliki Asimopoulou-Marinou, Marinos Pitsikalis* \\ Industrial Chemistry Laboratory, Department of Chemistry, National and Kapodistrian University of \\ Athens, Panepistimiopolis Zografou, 15771 Athens Greece
}

\section{Patrina Paraskevopoulou}

Inorganic Chemistry Laboratory, Department of Chemistry, National and Kapodistrian University of Athens, Panepistimiopolis Zografou, 15771 Athens Greece

\begin{abstract}
Well defined redox responsive amphiphilic block copolymers of ethylene oxide, EO, and 2methacryloyloxyethyl ferrocenecarboxylate, MAEFc were prepared by atom transfer radical polymerization (ATRP). The synthetic procedure was monitored by size exclusion chromatography (SEC) and the block copolymers were characterized using ${ }^{1} H$ NMR spectroscopy. The self-assembly behavior of these amphiphilic copolymers was studied in aqueous solutions and in acetonitrile, both selective solvents for the PEO block. The formation of supramolecular structures (micelles and micellar aggregates) was revealed by Dynamic Light Scattering (DLS) using the CONTIN algorithm. The thermal properties of the block copolymers were investigated by differential scanning calorimetry (DSC) and thermogravimetric analysis (TGA). Cyclic voltammetry of PEO-b-PMAEFc copolymers in $\mathrm{CHCl}_{3}$ solutions revealed a single redox process, a quasireversible oxidation wave with very slow kinetics, attributed to the $F e^{I I} \rightarrow F e^{I I I}$ oxidation of the ferrocenyl units. The oxidation of the copolymers became more difficult and that the kinetic reversibility of the redox process was diminished as the PEO/PMAEFc ratio in the polymer chain increased.
\end{abstract}

Keywords: block copolymers, micelles, ethylene oxide, 2-methacryloyloxyethyl ferrocenecarboxylate, thermal analysis, electrochemical properties, ATRP

\section{INTRODUCTION}

Organometallic polymers constitute a valuable class of building blocks for the synthesis of novel materials, due to their unusual catalytic, electrochemical, magentic and optical properties (1). Among them, metallocene-containing polymers (2) have attracted significant attraction over the last decades because of their numerous applications as catalysts, nanoceramic and biomedical materials (3), redox sensors for the recognition of sugars and ions (4), templates for the fabrication of nanotextured inorganic surfaces (5) and resists for block copolymer nanolithography (6) etc..

The metallocene motif can be incorporated either as an integral part of the polymeric backbone or as a lateral substituent. Undoubtedly, the most widely studied metallocene-containing polymers, are those bearing ferrocene moieties (7).

The first synthesis of ferrocene-containing polymers was reported by Arimoto and Haven in the 1950s with the free radical polymerization of vinylferrocene to afford low molecular weight products of broad molecular weight distribution. Further studies in the 1970s and 1980s involved the free radical, cationic and anionic polymerization of vinylferrocene, acrylates and methacrylates bearing ferrocene pendant groups, leading to the synthesis of side-chain organometallic polymers (8). In most cases, these efforts were characterized by a lack of control over the molecular weight and the molecular weight distribution and the inability to prepare well-defined complex macromolecular architectures.

A major advancement was reported by Manners on the living anionic ring opening polymerization of silaferrocenophanes in the 1990s, which opened a new era in the field of metallopolymers, leading to the synthesis of well-defined main-chain organometallic-based block copolymers (9). These 
copolymers developed fascinating magnetic, optical and electronic properties (10). More recently, the controlled ring opening metathesis polymerization of ansa-(vinylene) ferrocene $\mathrm{Fe}\left(\eta-\mathrm{C}_{5} \mathrm{H}_{3}{ }_{3} \mathrm{Bu}\right)_{2} \mathrm{C}_{2} \mathrm{H}_{2}$ with ${ }^{t} \mathrm{Bu}$ substituents on the cyclopentadienyl ligands was reported (11). Anionic polymerization techniques were also employed for the living polymerization of vinylferrocene and ferrocenylmethyl methacrylate leading to block copolymers with narrow molecular weight distributions (12). Atom transfer radical polymerization has been applied as well for the controlled polymerization of acrylates and methacrylates bearing ferrocenes as side ester groups $(13,14)$.

Block copolymers have attracted significant scientific and economic interest over the last few decades, mainly due to their ability for self-assembly into ordered structures (17). In bulk, selfassembly leads to characteristic morphological patterns, such as cylinders, spheres, lamellae, gyroid etc. $(17,18)$. In a selective solvent, i.e. a thermodynamically good solvent for the one block and precipitant for the other, block copolymers associate and form micellar aggregates (19). A large number of parameters such as temperature, solvent quality, concentration, $\mathrm{pH}$, copolymer molecular weight and composition may affect the aggregation behaviour, leading to a wide variety of micellar morphologies (spheres, cylinders, vesicles, lamellae etc.) $(19,20)$.

Enormous interest has been focused on the area of aqueous micellar systems, due to the wide range of their potential applications, such as detergency, surface coating, waste-water treatment, controlled drug delivery and oil recovery (21). Amphiphilic block copolymers with redox-active ferrocene groups have especially attracted extensive attention due to their potential applications in biomedicine, catalysis, nanotechnology and microelectronics (22).

In this work, we report the synthesis of block copolymers consisting of poly (ethylene oxide), PEO, and poly (2-methacryloyloxyethyl ferrocenecarboxylate), PMAEFc by atom transfer radical polymerization (ATRP) and the study of their self-assembly behavior in aqueous solutions and in acetonitrile, both selective solvents for the PEO chains. Their thermal and electrochemical properties were studied as well.

\section{EXPERIMENTAL SECTION}

\subsection{Materials}

MAEFc was prepared by the reaction of 2-hydroxyethyl methacrylate (Aldrich) with ferrocenylcarboxylic acid (Aldrich) in the presence of dicyclohexylcarbodiimide (DCC, Aldrich) and 4-di(methylamino)pyridine (DMAP, Aldrich) following literature procedures. The monomer was purified by column chromatography using a mixture of $n$-hexane and ethyl acetate $(v / v=10 / 1)$. The final product was obtained as a yellow solid (yield 80\%). All the products were characterized by ${ }^{1} \mathrm{H}$ NMR spectroscopy. Tetrahydrofuran (THF) and dichloromethane $\left(\mathrm{CH}_{2} \mathrm{Cl}_{2}\right)$ were purified according to literature. Poly (ethylene oxide) (PEO-OH), 2-bromo methylpropionyl bromide, copper(I) bromide $(\mathrm{Cu}(\mathrm{I}) \mathrm{Br}), \mathrm{N}, \mathrm{N}, \mathrm{N}$, N",N"'-pentamethyldiethylene triamine (PMDETA), $n$-hexane, ethyl acetate, triethylamine were purchased from Aldrich and used without further purification $(13,15)$.

\subsection{ATRP Macro-Initiator PEO-Br}

PEO-OH $(5000 \mathrm{~g} / \mathrm{mol})(0.002 \mathrm{~mol})$ was transformed into a macroinitiator, via an esterification reaction. A solution of 2-bromo methylpropionyl bromide $(0.006 \mathrm{~mol})$ in $\mathrm{CH}_{2} \mathrm{Cl}_{2}(10 \mathrm{ml})$ was added dropwise to a solution of PEO and TEA $(0.008 \mathrm{~mol})$ in a glass apparatus under high vacuum. The reaction was conducted at $0^{\circ} \mathrm{C}$ and then the mixture was stirred for $24 \mathrm{~h}$ at room temperature according to literature procedures. All the products were characterized by ${ }^{1} \mathrm{H}$ NMR spectroscopy (16).

\subsection{Polymerization of MAEFc with PEO-Br Macroinitiator}

The macroinitiator $(0.001 \mathrm{~mol})$ with $\mathrm{M}_{\mathrm{n}}=5000 \mathrm{~g} / \mathrm{mol}, \mathrm{MAEFc}$, and $\mathrm{CuBr}(0.004 \mathrm{~mol})$ were added in a specially designed glass apparatus. The ligand PMDETA (0.004 mol) was injected into the reaction flask through a septum of a side tube. After the injection, the tube was flame sealed and the apparatus was degassed. THF (10ml) was then distilled from the vacuum line, and the mixture was degassed for another time. The flask was removed from the line by heat sealing. The solution was stirred for 15 minutes at room temperature. The polymerization was performed at $60^{\circ} \mathrm{C}$ for $24 \mathrm{~h}$. The copolymers were precipitated in hexane where the monomer is soluble, then purified through a silica gel column in order to retain the catalyst and finally dried under vacuum. The final product was obtained as an orange solid. All the products were characterized by SEC and ${ }^{1} \mathrm{H}$ NMR spectroscopy. 
Amphiphilic Block Copolymers of Ethylene Oxide and 2 Methacryloyloxyethyl Ferrocenecarboxylate: Self-Assembly Behavior, Thermal and Electrochemical Properties

\subsection{Preparation of Micellar Solutions of PEO-b-PMAEFc Block Copolymers}

Two different methods were employed in order to prepare the micellar solutions. The first method was adopted for the aqueous solutions. According to this, $0.03 \mathrm{~g}$ of the polymer were poorly dissolved in $15 \mathrm{ml}$ of water, followed by addition of $3 \mathrm{ml}$ of the common good solvent THF to facilitate dissolution. The mixture was then heated to $60^{\circ} \mathrm{C}$ for $12 \mathrm{~h}$ to evaporate the volatile THF. The second method was followed for the acetonitrile solutions. In this case, $0.03 \mathrm{~g}$ of the polymer were dissolved directly in $15 \mathrm{ml}$ of acetonitrile, followed by mild heating at $65^{\circ} \mathrm{C}$ for at least 12 hours.

\subsection{Characterization Techniques}

Size Exclusion Chromatography (SEC) experiments were carried out at $40^{\circ} \mathrm{C}$ using a modular instrument consisting of a Waters model 510 pump, U6K sample injector, 401 refractometer, $486 \mathrm{UV}$ spectrophotometer, and a set of $5 \mu$-Styragel columns with a continuous porosity range from 500 to $106 \AA$. The columns were housed in an oven thermostatted at $40^{\circ} \mathrm{C} . \mathrm{CHCl}_{3}$ was the carrier solvent at a flow rate of $1 \mathrm{~mL} / \mathrm{min}$. The system was calibrated with nine PS standards having molecular weights in the range of $970-600,000$.

Static light scattering measurements were performed with a Chromatix KMX-6 low angle laser light scattering photometer at $25^{\circ} \mathrm{C}$ equipped with a $2 \mathrm{~mW}$ He-Ne laser operating at $\lambda=633 \mathrm{~nm}$. The equation (1) describing the concentration dependence of the reduced intensity is:

$\mathrm{Kc} / \Delta \mathrm{R}_{\theta}=1 / \mathrm{M}_{\mathrm{w}, \text { app }}+2 \mathrm{~A}_{2} \mathrm{c}+\ldots$

where $\mathrm{K}$ is a combination of optical and physical constants, including the refractive index increment, $\mathrm{dn} / \mathrm{dc}$, and the excess Rayleigh ratio of the solution over that of the solvent, $\Delta \mathrm{R}_{\theta}$. Stock solutions were prepared, followed by dilution with solvent to obtain appropriate concentrations. All solutions and solvents were optically clarified by filtering through $0.22 \mu \mathrm{m}$ pore size nylon filters directly into the scattering cell.

Refractive index increments, $\mathrm{dn} / \mathrm{dc}$, at $25^{\circ} \mathrm{C}$ were measured with a Chromatix KMX-16 refractometer operating at $633 \mathrm{~nm}$ and calibrated with aqueous $\mathrm{NaCl}$ solutions.

Dynamic light scattering measurements were conducted with a Series 4700 Malvern system composed of a PCS5101 goniometer with a PCS stepper motor controller, a Cyonics variable power $\mathrm{Ar}^{+}$laser, operating at $488 \mathrm{~nm}$, a PCS8 temperature control unit, a RR98 pump/filtering unit and a 192 channel correlator for the accumulation of the data. The correlation functions were analyzed by the cumulant method and the CONTIN software. Measurements were carried out at $45^{\circ}, 60^{\circ}, 90^{\circ}$ and $135^{\circ}$. The angular dependence of the ratio $\Gamma / \mathrm{q}^{2}$, where $\Gamma$ is the decay rate of the correlation function and $\mathrm{q}$ is the scattering vector, was not very important for most of the micellar solutions. In these cases apparent translational diffusion coefficients at zero concentration, $\mathrm{D}_{\mathrm{o}, \text { app }}$ were measured using the equation (2):

$\mathrm{D}_{\text {app }}=\mathrm{D}_{\mathrm{o}, \mathrm{app}}\left(1+\mathrm{k}_{\mathrm{D}} \mathrm{c}\right)$

where $\mathrm{k}_{\mathrm{D}}$ is the coefficient of the concentration dependence of the diffusion coefficient. When there was angular dependence the diffusion coefficient was obtained from the slope of the $\Gamma / \mathrm{q}^{2} \mathrm{vs} q$ plot. Apparent hydrodynamic radii at infinite dilutions, $R_{h}$, were calculated by aid of the Stokes-Einstein equation (3):

$\mathrm{R}_{\mathrm{h}}=\mathrm{kT} / 6 \pi \eta_{\mathrm{s}} \mathrm{D}_{\mathrm{o}, \mathrm{app}}$

where $\mathrm{k}$ is the Boltzmann's constant, $\mathrm{T}$ the absolute temperature and $\eta_{\mathrm{s}}$ the viscosity of the solvent.

The glass-transition temperatures were obtained by differential scanning calorimetry (DSC) using a 2910 modulated DSC model from TA instruments. The samples were heated or cooled at a rate of $10^{\circ} \mathrm{C} / \mathrm{min}$. The second heating results were obtained in all cases.

The thermal stability of the copolymers was studied by thermogravimetric analysis (TGA) employing a Q50 TGA model from TA instruments. The samples were heated at a rate of $10^{\circ} \mathrm{C} / \mathrm{min}$ under nitrogen atmosphere.

The composition of copolymers was also determined from ${ }^{1} \mathrm{H}-\mathrm{NMR}$ spectra, which were recorded in chloroform-d at $30^{\circ} \mathrm{C}$ with a Varian Unity Plus 300/54 NMR spectrometer. 
Cyclic voltammetry was carried out with a Pine Instrument Company Bipotentiostat Model AFCBP1, controlled with the Aftermath 1.2.5876 software. Experiments were performed with Ar-degassed 10 $0^{-2}$ $\mathrm{M}$ solutions containing ${ }^{n} \mathrm{Bu}_{4} \mathrm{NPF}_{6}(0.5 \mathrm{M})$ as supporting electrolyte, using a gold (Au) disk working electrode (2 $\mathrm{mm}$ diameter) and a thin Pt foil or gauge $\left(8 \mathrm{~cm}^{2}\right.$, Sigma-Aldrich) as a counter electrode. A non-aqueous $\mathrm{Ag} / \mathrm{Ag}^{+}$reference electrode $\left(0.01 \mathrm{M} \mathrm{AgNO}_{3} / 0.5 \mathrm{M}^{n} \mathrm{Bu}_{4} \mathrm{NPF}_{6}\right.$ in DMF) was purchased from Bioanalytical Systems, Inc. and was contacted with the electrolytic solution through a long bridge $\left(80 \mathrm{~mm}\right.$ ) filled with $0.5 \mathrm{M}^{n} \mathrm{Bu}_{4} \mathrm{NPF}_{6}$ in DMF. The working electrode was first polished successively using 6,3 and $1 \mathrm{~mm}$ diamond paste on a DP-Nap polishing cloth (Struers, Westlake, $\mathrm{OH})$, then was washed with water and acetone and air-dried. The $\mathrm{Pt}$ foil and gauge counter electrodes were cleaned in a $\mathrm{H}_{2} \mathrm{O}_{2} / \mathrm{H}_{2} \mathrm{SO}_{4}$ (conc) solution (1:4 v:v) and oven-dried. The potential sweep rate varied in the range of $40-500 \mathrm{mV} / \mathrm{s}$. All potentials are reported versus the ferrocenium/ferrocene $\left(F c^{+} / F c\right)$ couple.

\section{RESULTS AND DISCUSSION}

\subsection{Synthesis and Characterization of PEO-b-PMAEFc Amphiphilic Block Copolymers}

The organometallic monomer MAEFc was successfully synthesized via an esterification reaction between ferrocene carboxylic acid and hydroxyethyl methacrylate following literature procedures. The chemical structure of MAEFc was verified by $1 \mathrm{H}$ NMR. The double bond protons resonate at 6.19 and $5.62 \mathrm{ppm}$. The peaks at 4.19, 4.40 and $4.81 \mathrm{ppm}$ correspond to nine protons of the ferrocenyl group, whereas the signals at $4.46 \mathrm{ppm}$ correspond to the four protons of the moiety $\mathrm{OCH}_{2} \mathrm{CH}_{2} \mathrm{OC}=\mathrm{O}$ $(13,14)$.

PEO-Br was obtained via an esterification reaction by reacting hydroxyl-ended PEO with 2bromoisobutyryl bromide (Scheme 1). The ${ }^{1} \mathrm{H}$ NMR spectrum confirmed the efficient introduction of Br-containing ATRP initiating group. Liu et al. and Tang et al. reported the preparation of a PEO macroinitiator suitable to initiate the ATRP of MAEFC in order to synthesize PEO-b-PMAEFc amphiphilic diblock copolymers and PEO- $b$-PMAEFc- $b$-PSt triblock terpolymers, respectively (14).

The ATRP of MAEFc was then initiated by PEO-Br in the presence of $\mathrm{CuBr} / \mathrm{PMDETA}$ (Scheme 2). The well-controlled polymerization of MAEFc was manifested by the relatively low polydispersity index of the copolymers, the quantitative polymerization yield and the good agreement between the stoichiometric and the experimentally observed molecular weights of the copolymers. Specifically, the signals of the MAEFc monomer's double bond at 6.19 and $5.62 \mathrm{ppm}$ disappeared indicating the complete consumption of the methacrylate monomer. The composition of the polymers was determined by the ${ }^{1} \mathrm{H}$ NMR spectrum employing the characteristic peaks of $\mathrm{PEO}$ macroinitiator at $3.66 \mathrm{ppm}$ and the characteristic peaks of PMAEFc at $4.46 \mathrm{ppm}\left(\mathrm{OCH}_{2} \mathrm{CH}_{2} \mathrm{OC}=\mathrm{O}\right)$, at $4.41 \mathrm{ppm}$ at $4.81 \mathrm{ppm}$ and at $4.19 \mathrm{ppm}$ (ferrocenyl ring). The number average molecular weights were determined by ${ }^{1} \mathrm{H}$ NMR using the molecular weight of the PEO first block and the copolymers' compositions. The molecular weights of the diblocks were also evaluated by SEC. It has to be mentioned that the molecular weight of the PEO-Br macroinitiator is the same for all the samples equal to $5000 \mathrm{~g} / \mathrm{mol}$. Three amphiphilic block copolymers with varying composition of PMAEFc block were successfully prepared with relatively narrow molecular weight distributions. The results are summarized in Table 1. It is obvious that the molecular weights of the copolymers evaluated from ${ }^{1} \mathrm{H}$ NMR and SEC are quite similar.

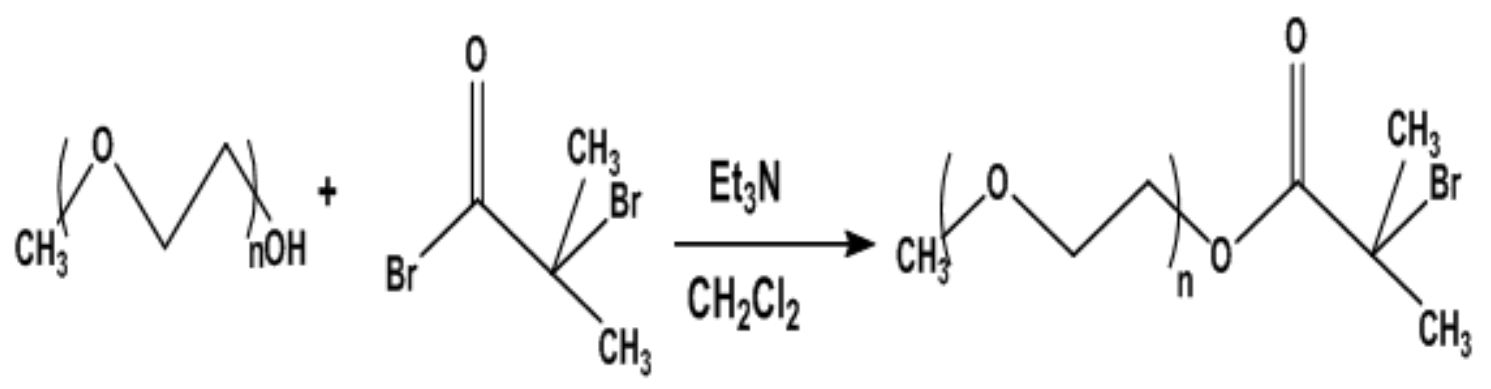

Scheme1. Synthesis of ATRP macroinitiator based on PEO 


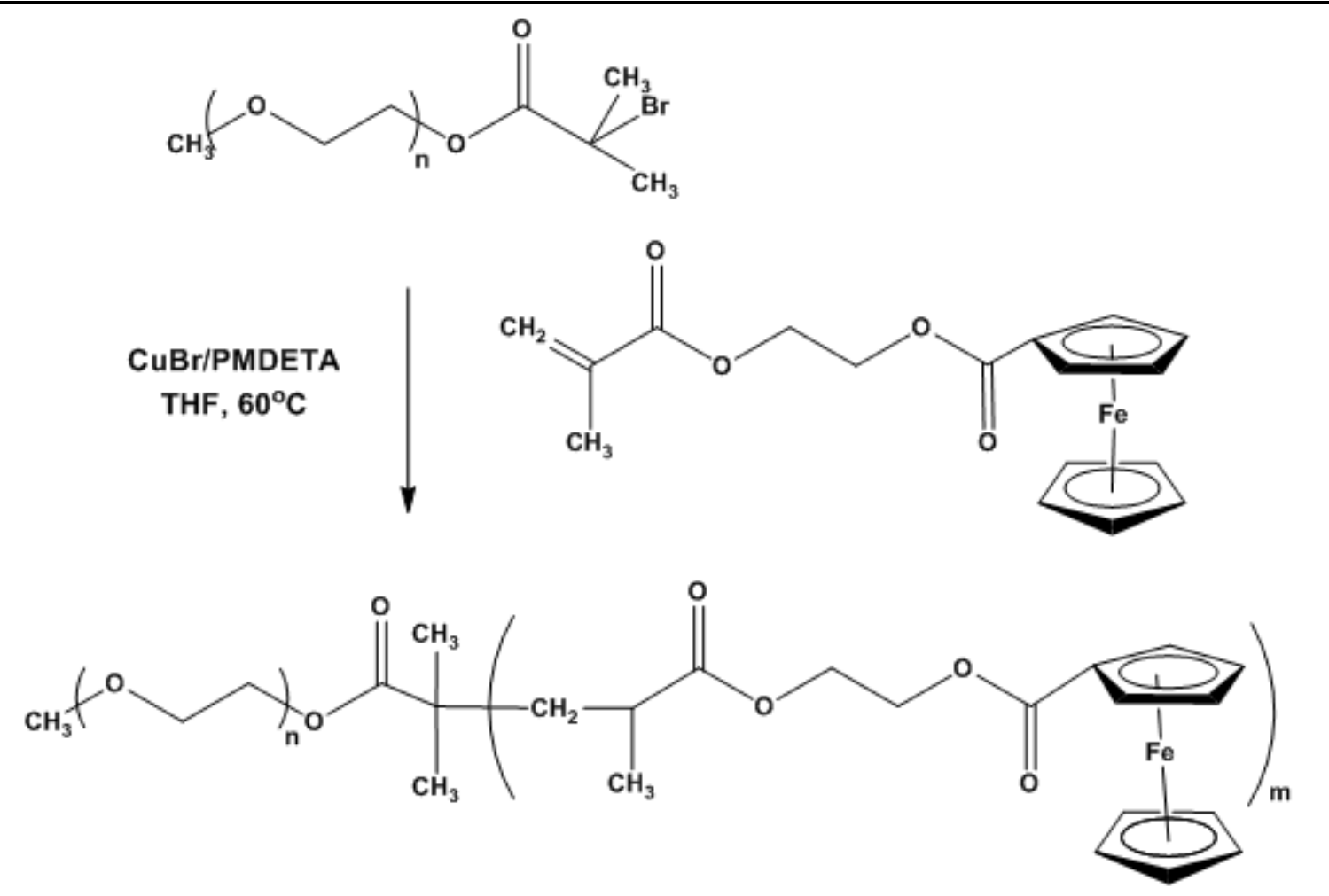

Scheme2. Synthesis of the PEO-b-PMAEFc block copolymers

Table1. Molecular characteristics of the PEO-b-PMAEFc block copolymers

\begin{tabular}{|c|c|c|c|c|c|c|c|}
\hline Sample & $\begin{array}{c}\mathbf{M}_{\mathbf{n}}{ }^{{ }^{2}} \\
(\mathrm{~g} / \mathrm{mol})\end{array}$ & $\begin{array}{c}M_{n}^{b} \\
(g / m o l)\end{array}$ & $\mathbf{I}^{\mathbf{a}}$ & $\begin{array}{c}\% \text { mol }^{\mathrm{b}} \\
\text { MAEFc }\end{array}$ & $\begin{array}{c}\% \text { mol }^{\mathrm{b}} \\
\text { PEO }\end{array}$ & $\begin{array}{c}\% \text { wt }^{\mathrm{b}} \\
\text { MAEFc }\end{array}$ & $\% \mathrm{wt}^{\mathrm{b}}$ PEO \\
\hline 1 & 6700 & 8200 & 1.1 & 8 & 92 & 40 & 60 \\
\hline 2 & 7900 & 9260 & 1.1 & 10 & 90 & 45 & 55 \\
\hline 3 & 17800 & 16670 & 1.2 & 25 & 75 & 70 & 30 \\
\hline
\end{tabular}

a: by SEC in THF

b: by ${ }^{l} H N M R$

\subsection{Self-Assembly Behavior of PEO-b-PMAEFc Amphiphilic Block Copolymers in Aqueous Solutions}

The copolymers are composed of a hydrophilic and a hydrophobic block. Therefore, they form aggregates in aqueous solutions with the polymethacrylate blocks at the micellar core and the PEO chains at the surrounding corona. Direct dissolution in water is not always feasible and may lead to non-equilibrium structures. Consequently, the samples were dissolved in a mixture of the selective solvent, water, and the common good solvent, THF. THF is miscible with water and has a low boiling point, compared to water. In this mixture of solvents, the samples are molecularly dissolved. The gradual evaporation of THF upon heating the solution for at least $12 \mathrm{hrs}$ at $60^{\circ} \mathrm{C}$ leads to the gradual association of the amphiphilic block copolymers and to equilibrium structures. Dynamic light scattering measurements were conducted in aqueous solutions to determine the hydrodynamic radius of the micellar structures formed by the block copolymers. The angular dependence of the diffusion coefficient was checked by performing measurements at different angles from $45^{\circ}$ up to $135^{\circ}$. The thermal dependence of the hydrodynamic radius was also determined by heating the solutions gradually up to $55^{\circ} \mathrm{C}$ and then cooling down to room temperature. The results are summarized in Table 2.

Table2. DLS data for the PEO-b-PMAEFc block copolymers in aqueous solutions

\begin{tabular}{|c|c|c|}
\hline Sample & $\mathbf{D}_{\mathbf{0}, \mathbf{a p p}}$ & $\mathbf{R}_{\mathbf{h}} \mathbf{( \mathbf { n m } )}$ \\
\hline $\mathbf{1}$ & $2.3340 \times 10^{-8}$ & 105.16 \\
\hline $\mathbf{2}$ & $6.1823 \times 10^{-8}$ & 39.64 \\
\hline $\mathbf{3}$ & $6.4812 \times 10^{-8}, 1.2371 \times 10^{-8}$ & $37.81,198.09$ \\
\hline
\end{tabular}


CONTIN analysis for sample 1 revealed that there is only one population in solution. The polydispersity factor $\mu_{2} / \Gamma^{2}$, where $\Gamma$ is the decay rate of the correlation function and $\mu_{2}$ the second moment of the cumulant analysis, is always higher than 0.2 , indicating the presence of polydisperse aggregates. Angular dependence was obvious meaning that the aggregates were not spherical. The diffusion coefficient was obtained from the slope of the $\Gamma / \mathrm{q}^{2} \mathrm{vs} q$ plot leading finally to a hydrodynamic radius, $\mathrm{R}_{\mathrm{h}}$ equal to $105.2 \mathrm{~nm}$ (Figure 1). Taking into account the relatively low composition in the hydrophobic block PMAEFc, it can be concluded that rather loose and nonuniform micelles exist in the solution. Thermal dependence was not observed for all concentrations leading to the conclusion that thermally stable loose micelles are formed (Figure 2).

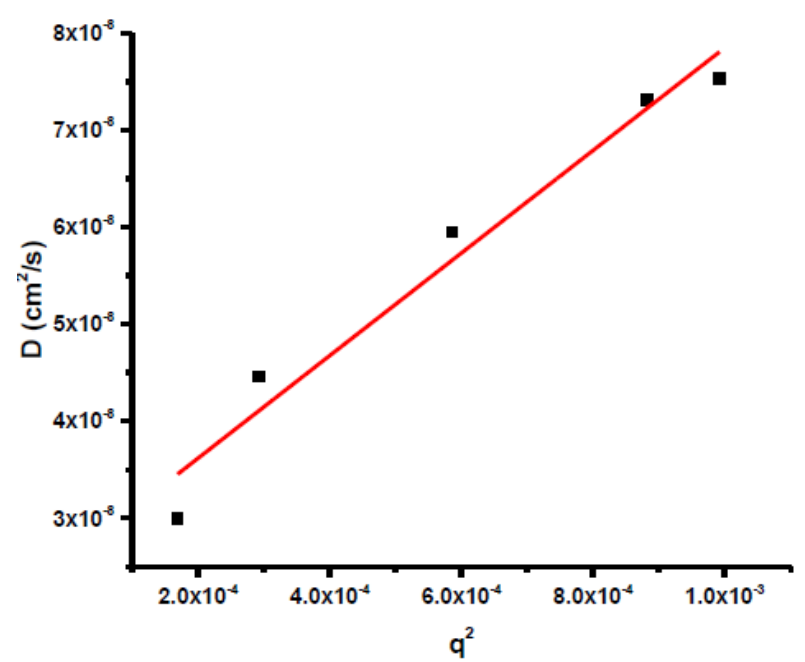

Figure1a. Angular dependence of $D$ for sample $1\left(c=7.482 \times 10^{-4} \mathrm{~g} / \mathrm{ml}\right)$ in aqueous solution

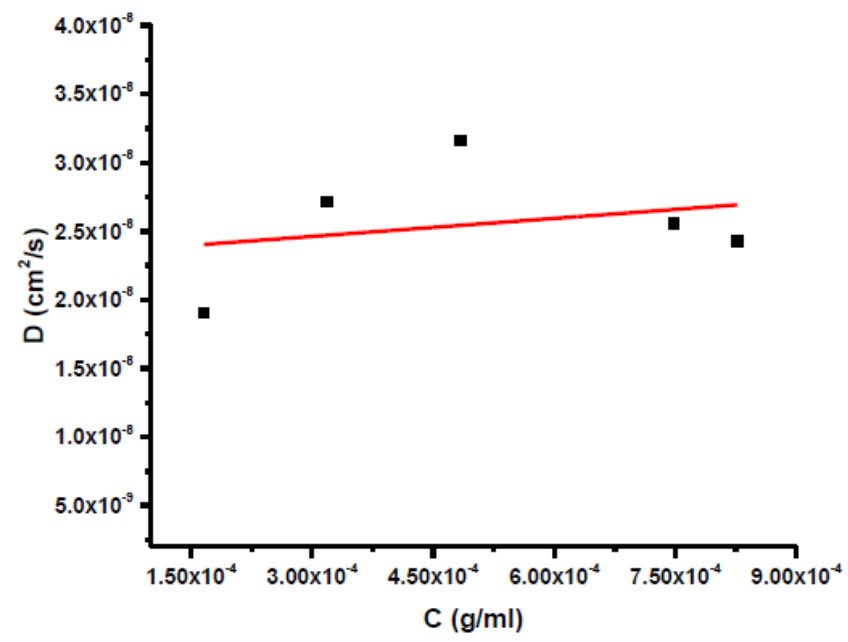

Figure1b. DLS plot for sample 1 in aqueous solution

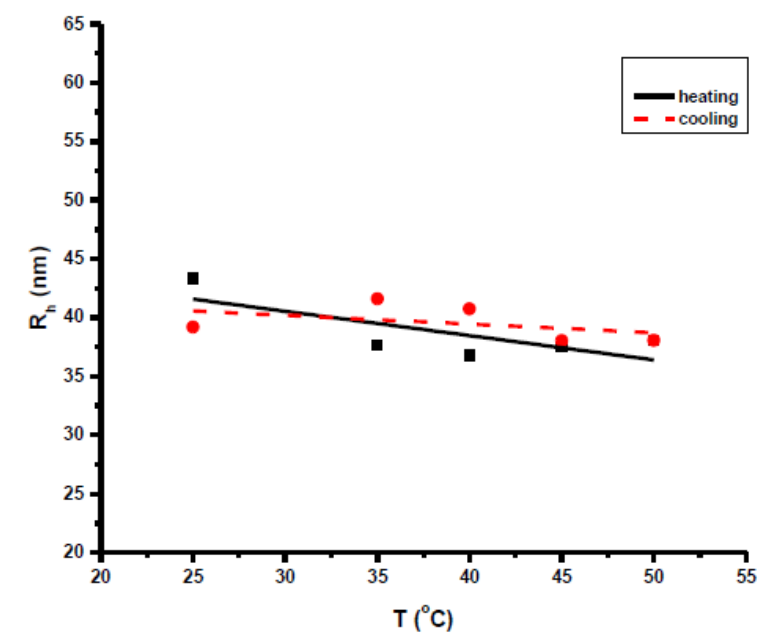

Figure2. Temperature dependence of $R_{h}$ for sample $1\left(c=8.266 \times 10^{-4} \mathrm{~g} / \mathrm{ml}\right)$ in aqueous solution 
Amphiphilic Block Copolymers of Ethylene Oxide and 2 Methacryloyloxyethyl Ferrocenecarboxylate: Self-Assembly Behavior, Thermal and Electrochemical Properties

Upon increasing the polymethacrylate content to sample 2 more compact, spherical and thermally stable micelles are formed. These conclusions can be derived judging from the lack of angular and thermal dependence for all concentrations, the single population revealed by CONTIN analysis with a lower $\mathrm{R}_{\mathrm{h}}$ value (equal to $39.64 \mathrm{~nm}$ ) and the rather low $\mu_{2} / \Gamma^{2}$ values, meaning that the micellar structures are more uniform than those coming from sample 1 (Figure 3, Figure 4). The higher degree of association of sample 2 compared to that of sample 1 is manifested by its lower $k_{D}$ value $\left(k_{D}=-\right.$ 182.2 for sample 2 instead of $k_{D}=187.5$ for sample 1 ). The very small and negative $k_{D}$ value is associated with a very small second virial coefficient $\mathrm{A}_{2}$ value and therefore with a high degree of association in agreement with the equation:

$\mathrm{k}_{\mathrm{D}}=2 \mathrm{~A}_{2} \mathrm{M}+\mathrm{k}_{\mathrm{f}}-\mathrm{u}$

where $\mathrm{M}$ is the micellar molecular weight, $\mathrm{k}_{\mathrm{f}}$ the coefficient of the concentration dependence of the friction coefficient and $u$ the partial specific volume of the polymer. $\mathrm{k}_{\mathrm{D}}$ is a dynamic interaction parameter incorporating both thermodynamic interactions, manifested in $\mathrm{A}_{2}$, and hydrodynamic interactions, manifested in $\mathrm{k}_{\mathrm{f}}(23)$.

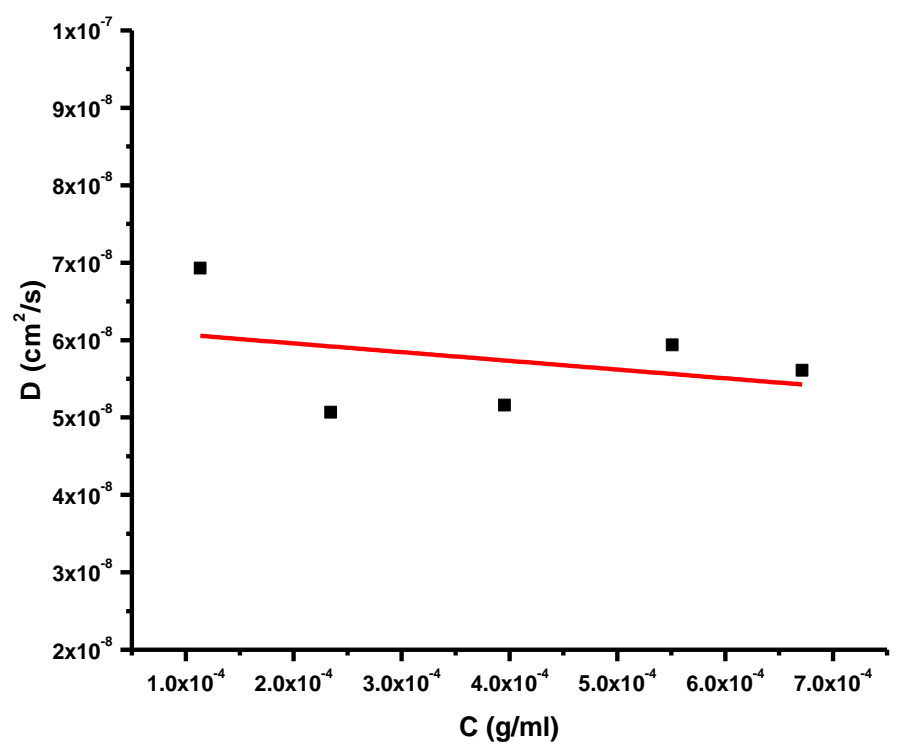

Figure3. DLS plot for sample 2 in aqueous solution

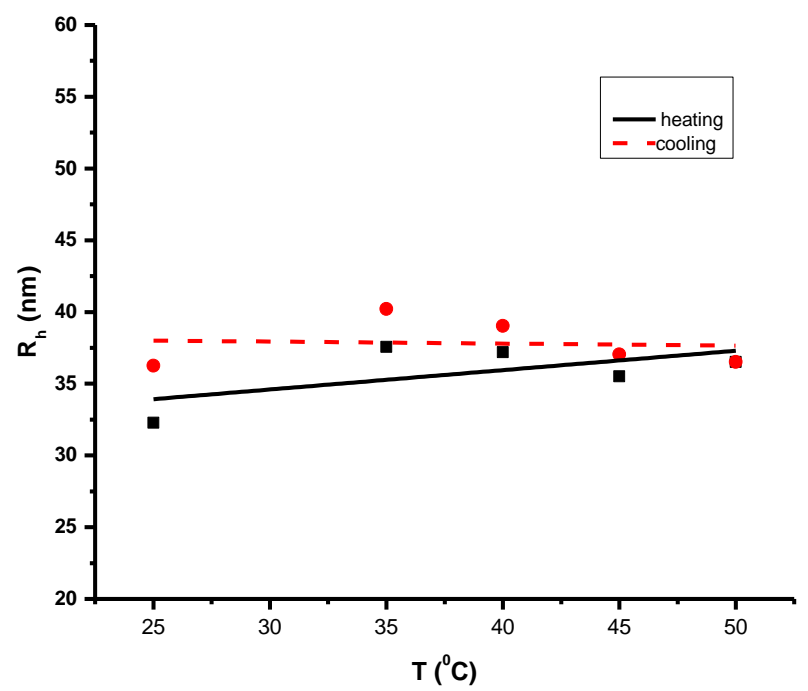

Figure4. Temperature dependence of $R_{h}$ for sample $2\left(c=5.510 \times 10^{-4} \mathrm{~g} / \mathrm{ml}\right)$ in aqueous solution 
A further increase of the PMAEFc content leads to a different aggregation behavior. CONTIN analysis showed the existence of a bimodal distribution with $\mathrm{R}_{\mathrm{h} 1}=37.81 \mathrm{~nm}$ and $\mathrm{R}_{\mathrm{h} 2}=198.1 \mathrm{~nm}$ indicating an equilibrium between micelles and micellar aggregates. The angular dependence was limited, meaning that both populations are almost spherical. In addition, both structures are thermally stable and their content does not change appreciably upon heating or increasing the concentration (Figure 5, Figure 6).

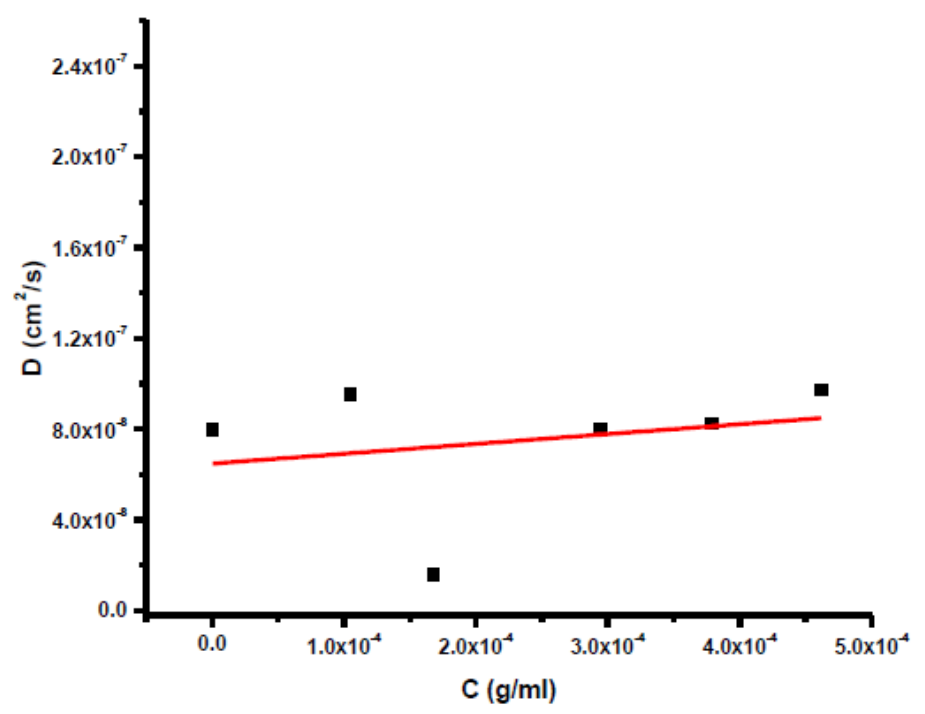

Figure5a. DLS plot for sample 3 (first population) in aqueous solution

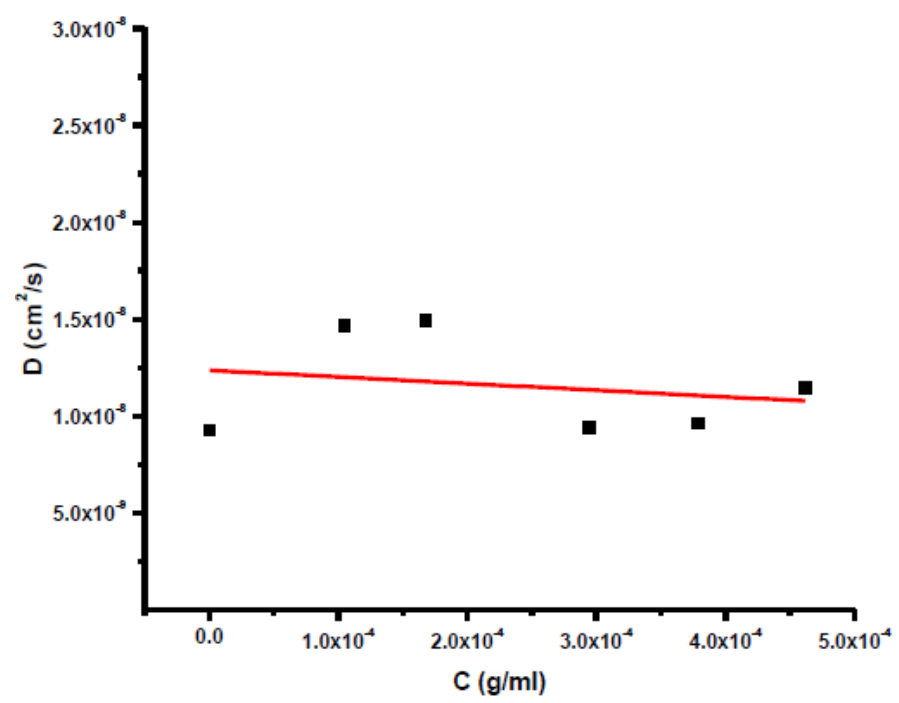

Figure5b. DLS plot for sample 3 (second population) in aqueous solution

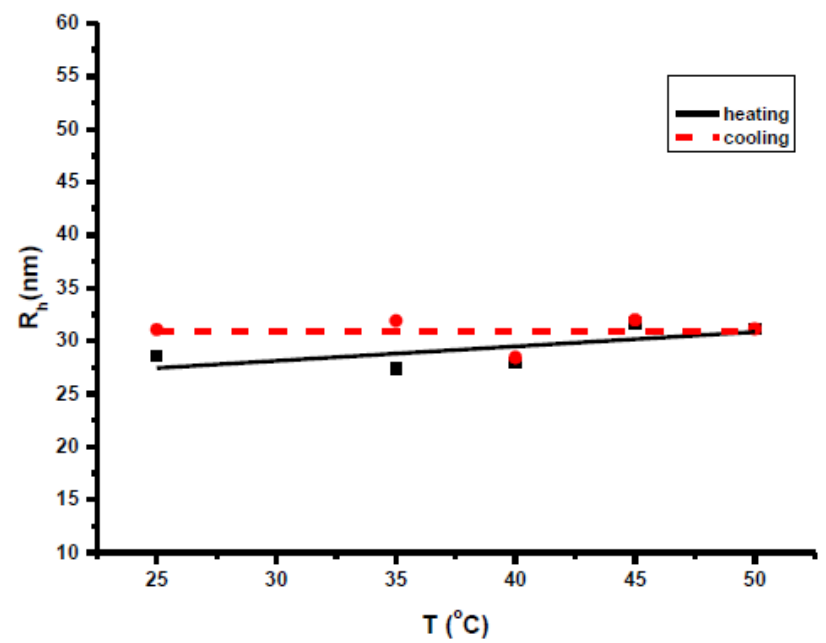

Figure6a. Temperature dependence of $R_{h}$ for sample $3\left(c=1.050 \times 10^{-4} \mathrm{~g} / \mathrm{ml}\right.$, first population) in aqueous solution 


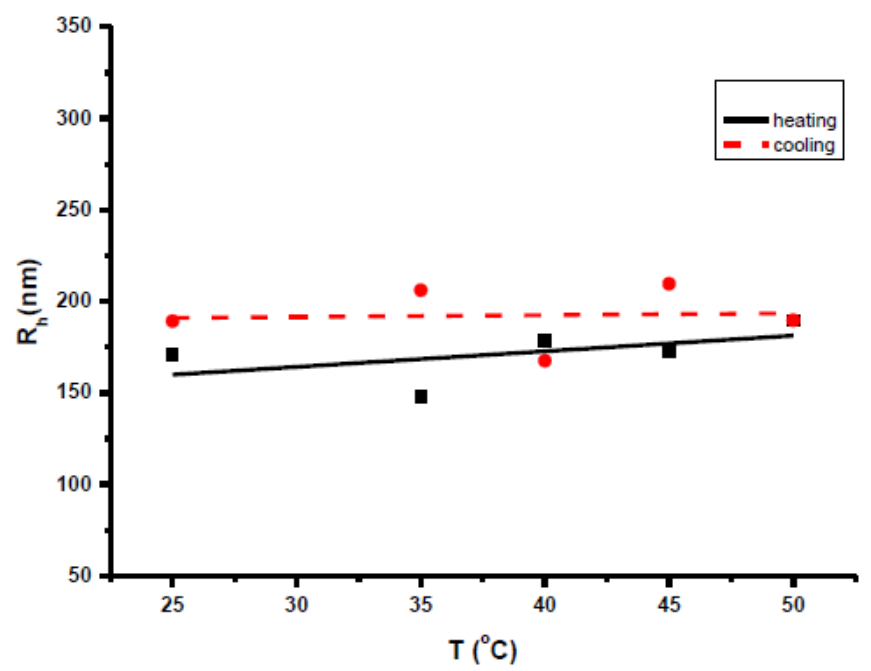

Figure6b. Temperature dependence of $R_{h}$ for sample $3\left(c=1.050 \times 10^{-4} \mathrm{~g} / \mathrm{ml}\right.$, second population) in aqueous solution

\subsection{Self-Assembly Behavior of PEO-b-PMAEFc Amphiphilic Block Copolymers in Acetonitrile}

Acetonitrile is a selective solvent for the PEO- $b$-PMAEFc copolymers, since it is a good solvent for the PEO blocks and a precipitant for the PMAEFc blocks. Micellar solutions were prepared by direct dissolution of the copolymer in the selective solvent. The micellization procedure was facilitated by heating the solution at $65^{\circ} \mathrm{C}$ for at least 12 hours. Heating the solution at a temperature equal to the glass transition temperature of PMAEFc, the core forming block, facilitates the formation of equilibrium micellar structures. This was confirmed by conducting static and dynamic light scattering measurements at different concentration regimes. In all cases the results were reproducible, verifying that stable equilibrium micelles exist in solution.

LALLS measurements were conducted for two samples, and the results are displayed in Table 3, whereas a characteristic $\mathrm{Kc} / \Delta \mathrm{R}_{\theta}$ vs $\mathrm{c}$ plot is given in Figure 7. Upon increasing the PMAEFc content the degree of association, $\mathrm{N}_{\mathrm{w}}$, is substantially increased. The second virial coefficients were negative for both samples, due to the higher apparent molecular weight of the micelles and the lack of interactions between the selective solvent and the polymethacrylate block, the core-forming component.

Table3. LALLS data of the PEO-b-PMAEFc block copolymers in acetonitrile

\begin{tabular}{|c|c|c|c|}
\hline Sample & $\mathbf{M}_{\mathbf{w}}$ & $\mathbf{A}_{\mathbf{2}}$ & $\mathbf{N}_{\mathbf{w}}$ \\
\hline 1 & 14400 & $-2.23 \times 10^{-3}$ & 1.8 \\
\hline 2 & 288700 & $-3.67 \times 10^{-4}$ & 31.2 \\
\hline
\end{tabular}

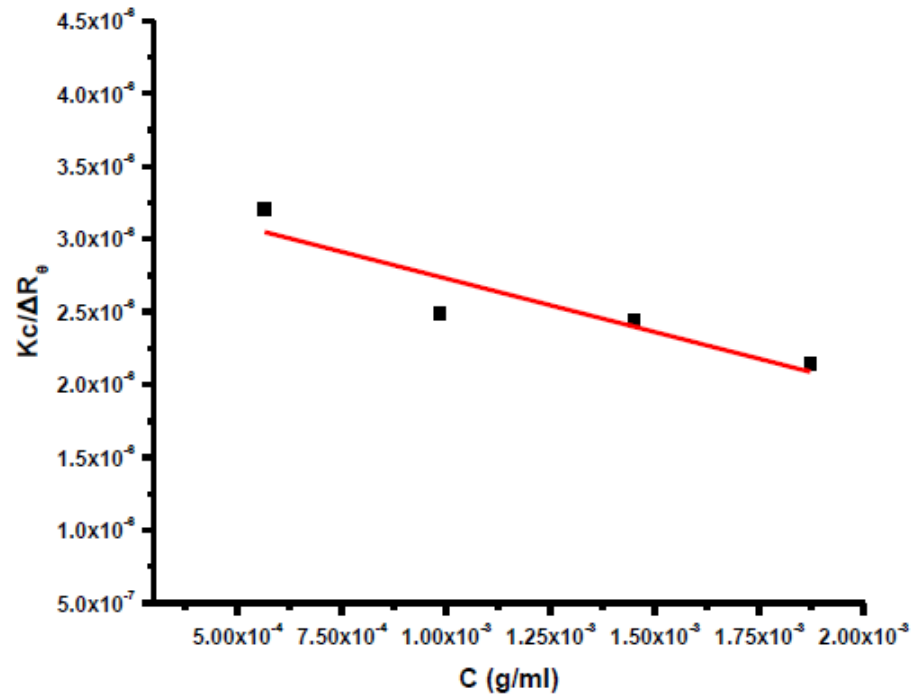

Figure7. LALLS plot for sample 2 in acetonitrile 


\section{Margarita Droulia et al.}

DLS measurements were also conducted in acetonitrile for all samples. The results are given in Table 4, whereas a characteristic plot D vs $\mathrm{c}$ is given in Figure 8. The $\mathrm{R}_{\mathrm{h}}$ values decrease upon increasing the PMAEFc content, indicating that gradually more compact micellar structures are produced. CONTIN analysis showed that there is only one population in solution corresponding to micelles. The rather high $\mu_{2} / \Gamma^{2}$ values $\left(\mu_{2} / \Gamma^{2}>0.2\right)$ indicate that the micelles are polydisperse. The lack of angular and thermal dependence of the measured $R_{h}$ values confirms that the micelles are spherical and thermally stable.

Table4. DPL data of the PEO-b-PMAEFc block copolymers in acetonitrile

\begin{tabular}{|c|c|c|}
\hline PEO-b-PMAEFc & $\mathbf{D}_{\mathbf{0}, \mathbf{a p p}}$ & $\left.\mathbf{R}_{\mathbf{h}} \mathbf{( n m}\right)$ \\
\hline $\mathbf{1}$ & $3.7913 \times 10^{-8}$ & 168.3 \\
\hline $\mathbf{2}$ & $1.4954 \times 10^{-7}$ & 42.68 \\
\hline $\mathbf{3}$ & $2.8729 \times 10^{-7}$ & 22.22 \\
\hline
\end{tabular}

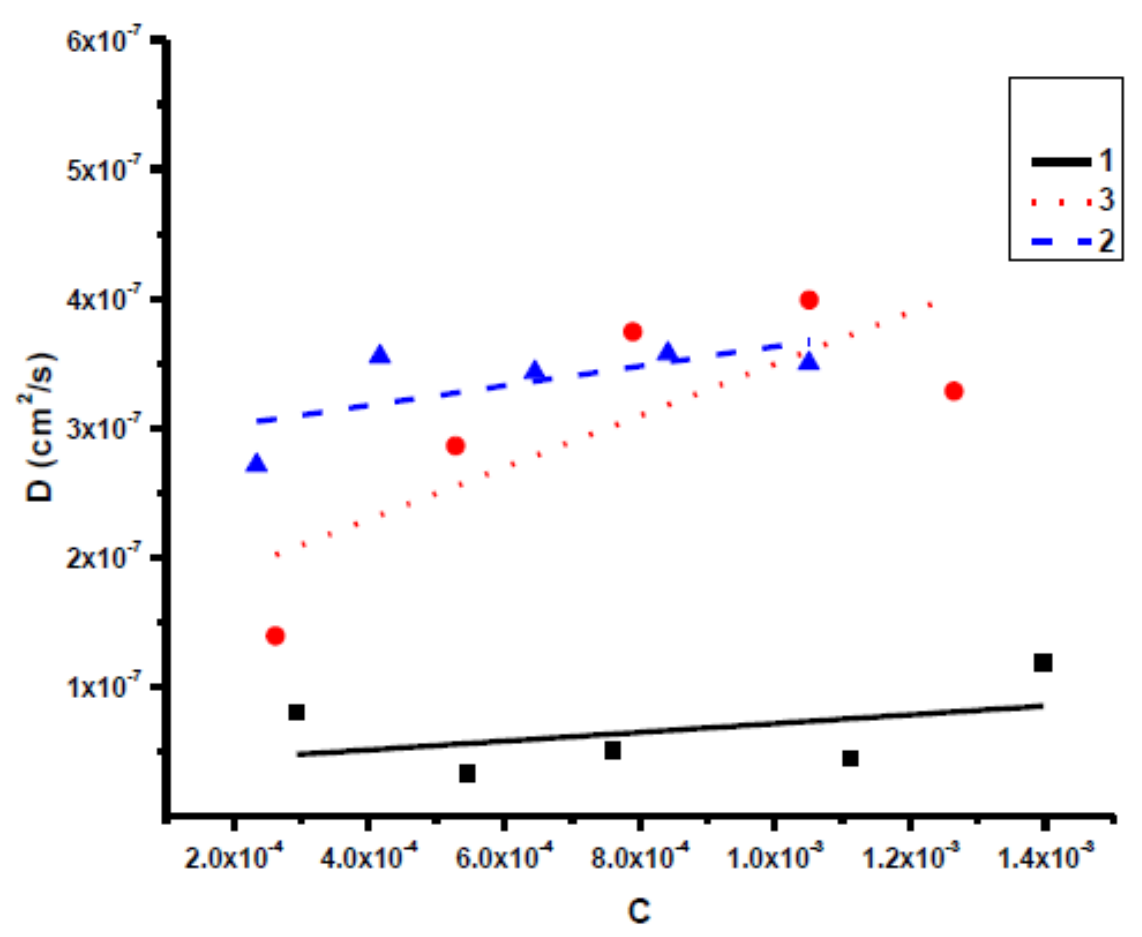

Figure8. DLS plots of the PEO-b-PMAEFc block copolymers in acetonitrile

Comparing the results in water and acetonitrile, it is obvious that the association in the organic solvent is less extensive and the micellar structures are smaller. Therefore, it is possible to manipulate the aggregation process by changing the quality of the solvent.

\subsection{Thermal Properties}

The thermal properties of the PEO- $b$-PMAEFc block copolymers were studied by DSC and TGA measurements. PEO is a semicrystalline polymer with $\mathrm{T}_{\mathrm{m}}=60^{\circ} \mathrm{C}$, whereas PMAEFc is amorphous having $\mathrm{Tg}=65.2^{\circ} \mathrm{C}$. The DSC results are given in Table 5, whereas a characteristic thermogram is shown in Figure 9. It is rather surprising that both the melting endotherm of the PEO block and the glass transition of the bulky polymethacrylate block are visible in the thermograms. The melting temperature of the PEO blocks is substantially suppressed due to both the rather low molecular weight of the PEO block and the restrictions in the organization of crystal structures imposed by the polymethacrylate block. On the other hand, the Tg values of the PMAEFc blocks were recorded to be very close to the $\mathrm{Tg}$ value of the pure homopolymer. These results indicate that despite their low molecular weights the block copolymers are microphase separated.

Table5. DSC data of the PEO-b-PMAEFc block copolymers

\begin{tabular}{|c|c|c|c|}
\hline PEO-b-PMAEFc & $\mathbf{T m}\left({ }^{\mathbf{0}} \mathbf{C}\right)$ & $\mathbf{T g}\left({ }^{\mathbf{0}} \mathbf{C}\right)$ & $\mathbf{\Delta H m}(\mathbf{J} / \mathbf{g})$ \\
\hline $\mathbf{1}$ & 49.49 & 62.54 & 5.334 \\
\hline $\mathbf{2}$ & 54.84 & 68.52 & 20.372 \\
\hline $\mathbf{3}$ & 49.49 & 66.10 & 5.301 \\
\hline
\end{tabular}




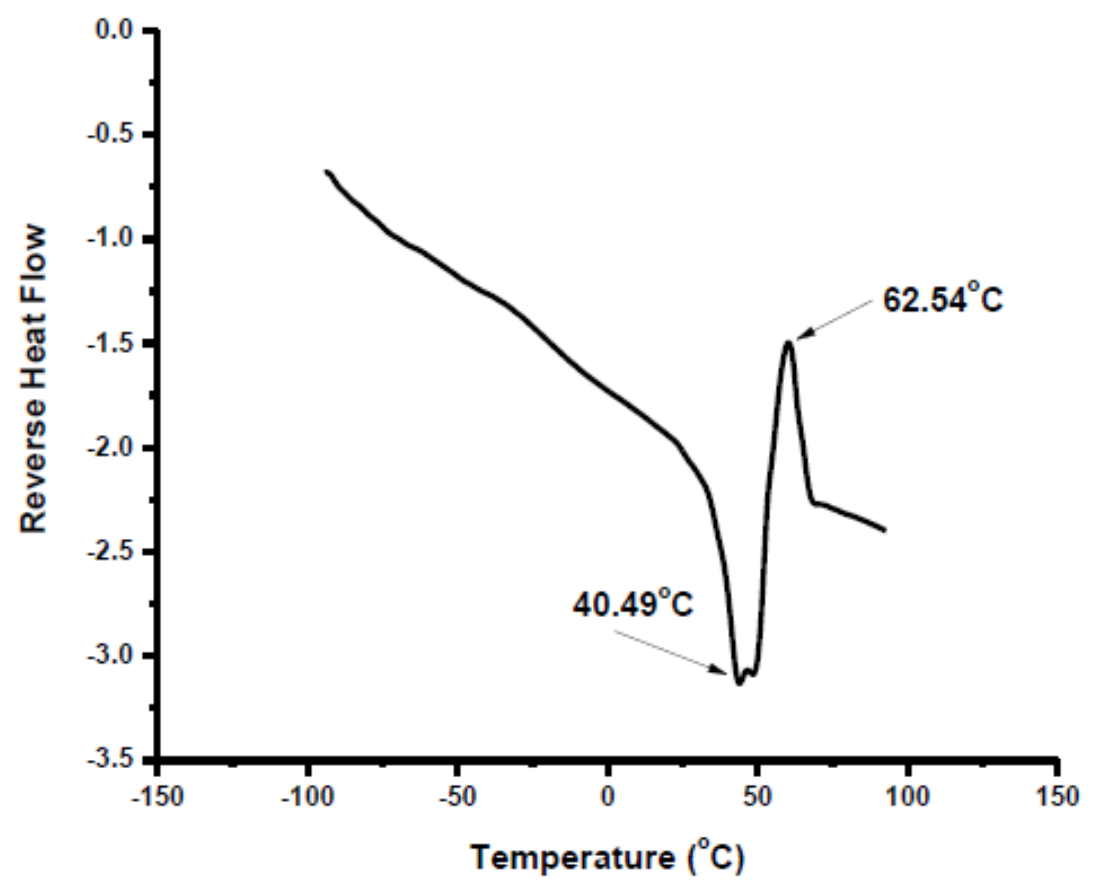

Figure9. DSC thermogram for sample 1

The thermal decomposition of the amphiphilic block copolymers was studied by TGA measurements, which were conducted under inert atmosphere of $\mathrm{N}_{2}$. The differential weight change is given in figure 10. In order to compare the results, the PEO and PMAEFc homopolymers were also included. All the samples were thermally stable at temperatures up to $200^{\circ} \mathrm{C}$. The thermal decomposition of PEO proceeds in a rather simple procedure. Differential thermogravimetry, DTG, showed that the decomposition is initiated at $308^{\circ} \mathrm{C}$ and is completed at $429.3^{\circ} \mathrm{C}$ with the maximum rate of decomposition being at $405^{\circ} \mathrm{C}$. On the other hand, PMAEFc reveals a more complex thermal decomposition pattern. It starts at $200^{\circ} \mathrm{C}$ and is completed at $428^{\circ} \mathrm{C}$, showing intermediate maxima at $281,332,364$ and $402.5^{\circ} \mathrm{C}$. The thermal decomposition of the block copolymers is a combination of the behavior of both blocks. The initiation of the decomposition is located at around $200^{\circ} \mathrm{C}$, and the completion occurs at approximately $450^{\circ} \mathrm{C}$. The decomposition pattern is complex, as in the case of PMAEFc with the peak at around $410^{\circ} \mathrm{C}$ being the most intense, since it is attributed to the decomposition of both blocks. The other characteristic peaks of PMAEFc are also visible in the copolymers. The residue is attributed to the remaining Fe after the thermal degradation.

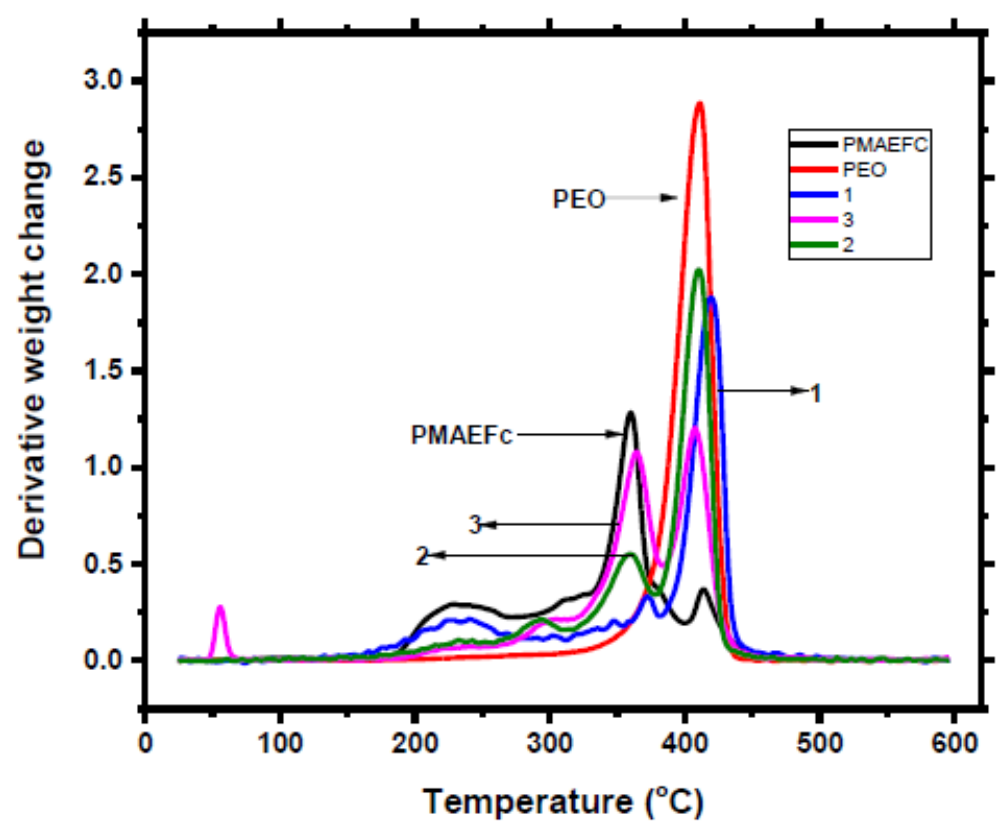

Figure10a. DTG results of the PEO-b-PMAEFc block copolymers 


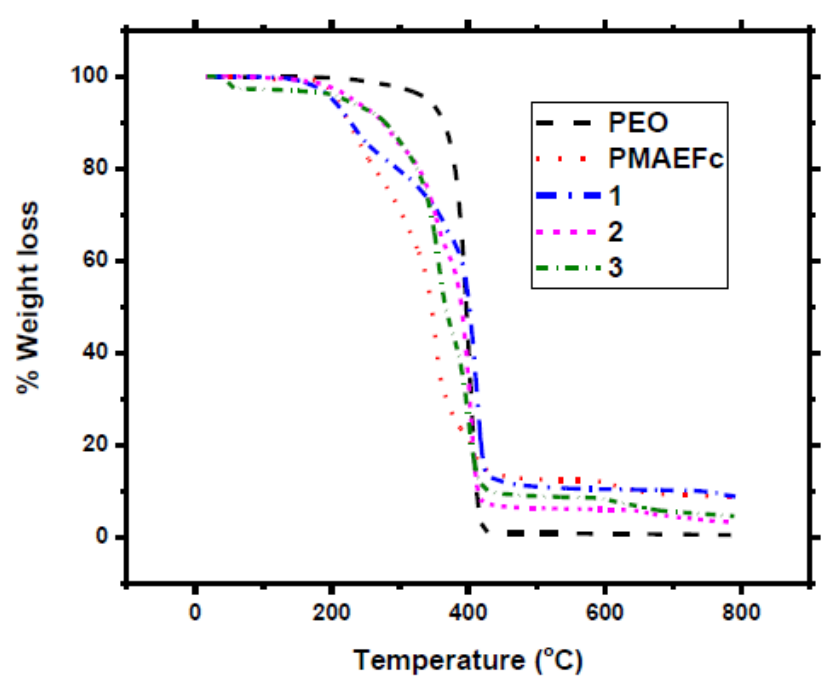

Figure10b. TGA results of the PEO-b-PMAEFc block copolymers

\subsection{Electrochemical Properties}

The redox behavior of PEO- $b$-PMAEFc copolymers was studied by cyclic voltammetry. Electrochemical data are collected in Table 6 . The precise $E_{1 / 2}$ values are to a certain extent not as precise due to adsorption on the electrode. All experiments were performed in $\mathrm{CHCl}_{3}$ solutions. The monomer exhibited a one-electron reversible oxidation wave in both $\mathrm{CHCl}_{3}$ and $\mathrm{MeCN}$ solutions at $E_{1 / 2}=0.246 \mathrm{~V}$ vs. $F c / F c^{+}\left(\mathrm{MeCN}: \Delta E=75 \mathrm{mV} ; i_{\mathrm{p}, \mathrm{a}} / i_{\mathrm{p}, \mathrm{c}}=1.08\right)(15)$. All copolymers exhibited a single redox process, attributed to the $\mathrm{Fe}^{\mathrm{II}} \rightarrow \mathrm{Fe}^{\mathrm{III}}$ oxidation of the ferrocenyl units. In any case, a quasireversible oxidation wave with very slow kinetics was observed. The cathodic wave showed distortion from the wave expected for a diffusion-controlled process, which is reminiscent to surface wave behavior. This was more evident in the case of sample 3 (bearing the highest MAEFc content), while the forward (anodic) wave has the characteristic shape for a diffusion-controlled process.

Table6. Electrochemical data of MAEFc, PMAEFc, and PEO-b-PMAEFC copolymers

\begin{tabular}{|c|c|c|c|c|c|}
\hline Compound & $\boldsymbol{E}_{\mathbf{p}, \mathbf{a}}\left(\mathbf{V} \boldsymbol{v s} . \boldsymbol{F c} / \boldsymbol{F c}^{+}\right)$ & $\begin{array}{c}\boldsymbol{E}_{\mathbf{p}, \mathbf{c}}(\mathbf{V} \boldsymbol{v s} . \\
\left.\boldsymbol{F} \boldsymbol{c} / \boldsymbol{F c}^{+}\right)\end{array}$ & $\begin{array}{c}\boldsymbol{E}_{\mathbf{1 / 2}}(\mathbf{V} \boldsymbol{v s} . \\
\left.\boldsymbol{F c} / \boldsymbol{F} \boldsymbol{c}^{+}\right)\end{array}$ & $\Delta \boldsymbol{E}(\mathbf{m V})$ & $\boldsymbol{i}_{\mathbf{p}, \mathbf{a}} / i_{\mathbf{p}, \mathbf{c}}$ \\
\hline MAEFc $^{a}$ & 0.283 & 0.208 & 0.246 & 75 & 1.08 \\
\hline PMAEFc $^{b}$ & 0.254 & 0.084 & 0.162 & 171 & 0.65 \\
\hline 1 & 0.960 & -0.224 & 0.368 & 1,184 & 0.95 \\
\hline 2 & 0.975 & -0.256 & 0.359 & 1,231 & 1.14 \\
\hline 3 & 1.056 & -0.534 & 0.261 & 1,590 & 0.90 \\
\hline
\end{tabular}

a: Solvent: $\mathrm{MeCN}(15)$.

b: Solvent: $\mathrm{CHCl}_{3}(15)$.

c: Solvent: $\mathrm{CHCl}_{3}$, this work.

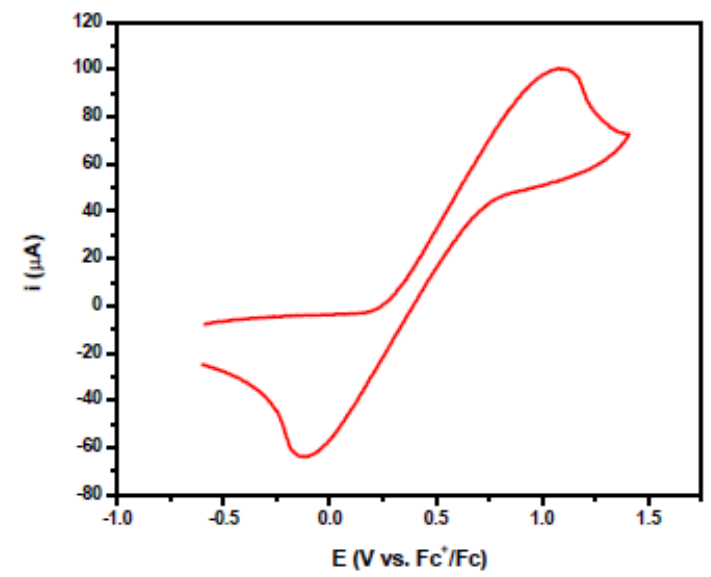

Figure11. Cyclic voltammogram $\left(\mathrm{Fe}^{I I} / \mathrm{Fe} e^{I I I}\right.$ ) of samples 1 (top), 2 (middle) and 3 (bottom) in $\mathrm{CHCl}_{3}{ }^{n} \mathrm{Bu}_{4} \mathrm{NPF} F_{6}$, with an Au disk electrode ( $2 \mathrm{~mm}$ in diameter), scan rate $0.1 \mathrm{~V} / \mathrm{s}$. 
Amphiphilic Block Copolymers of Ethylene Oxide and 2 Methacryloyloxyethyl Ferrocenecarboxylate: Self-Assembly Behavior, Thermal and Electrochemical Properties

This clearly indicates that the solubility of the copolymer changed (is reduced) upon oxidation and the insoluble oxidized form was adsorbed on the electrode surface (24). The current ratios $\left(i_{\mathrm{p}, \mathrm{a}} / i_{\mathrm{p}, \mathrm{c}}\right)$ were close to unity (0.90-1.14), indicating chemical reversibility. Deviations from unity are due to the fact that the cathodic wave combines diffusional and surface processes. Plots of current $\left(i_{\mathrm{p}}\right)$ vs. the sweep rate $(v)$ showed linear dependence of $i_{\mathrm{p}, \mathrm{a}}$ vs. $v^{1 / 2}$. However, $i_{\mathrm{p}, \mathrm{c}}$ did not show the same trend, especially at higher sweep rates. The voltammograms of samples 1 and 2 (Figure 12,13) were very similar, as expected, since the composition of the two polymers is also very similar.
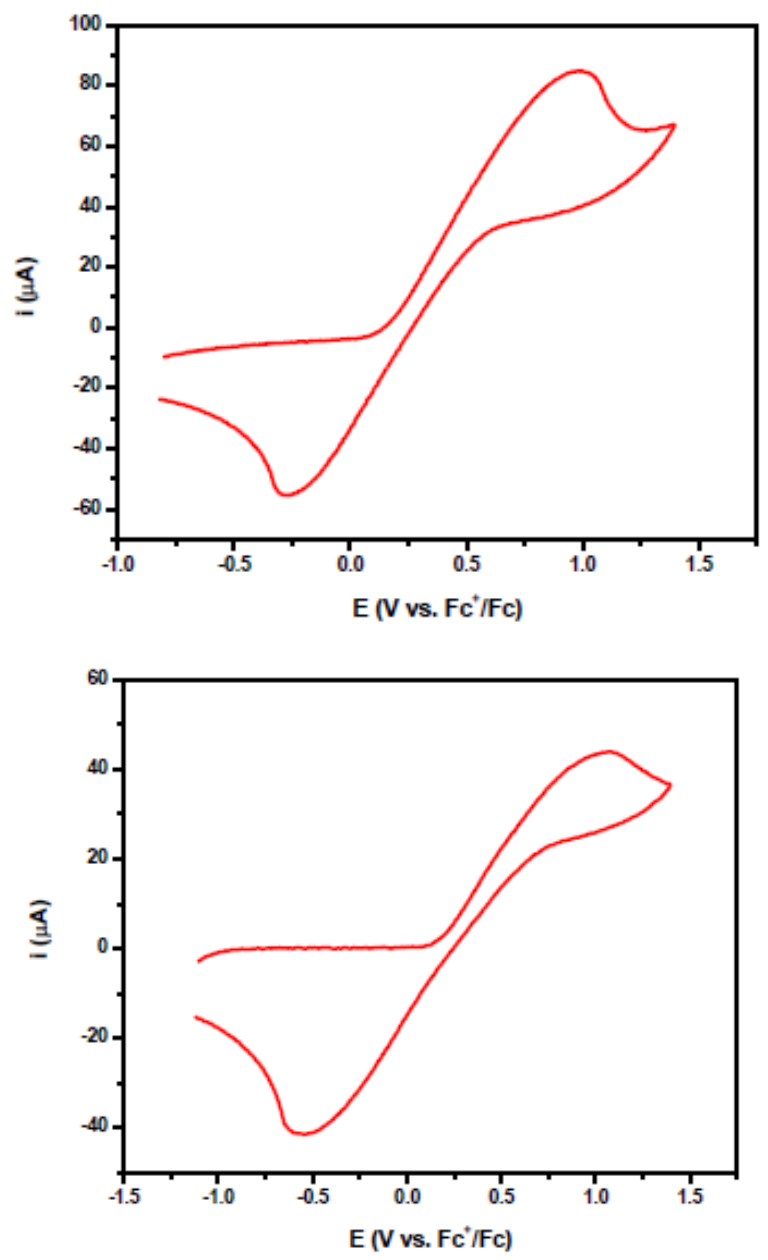

Figure12. Cyclic voltammogram $\left(\mathrm{Fe}^{\mathrm{II}} / \mathrm{Fe} \mathrm{III}^{I I I}\right.$ of sample 1 in $\mathrm{CHCl}_{3}{ }^{n} \mathrm{Bu}_{4} \mathrm{NPF}$, with an Au disk electrode $(2 \mathrm{~mm}$ in diameter) at different scan rates, as indicated

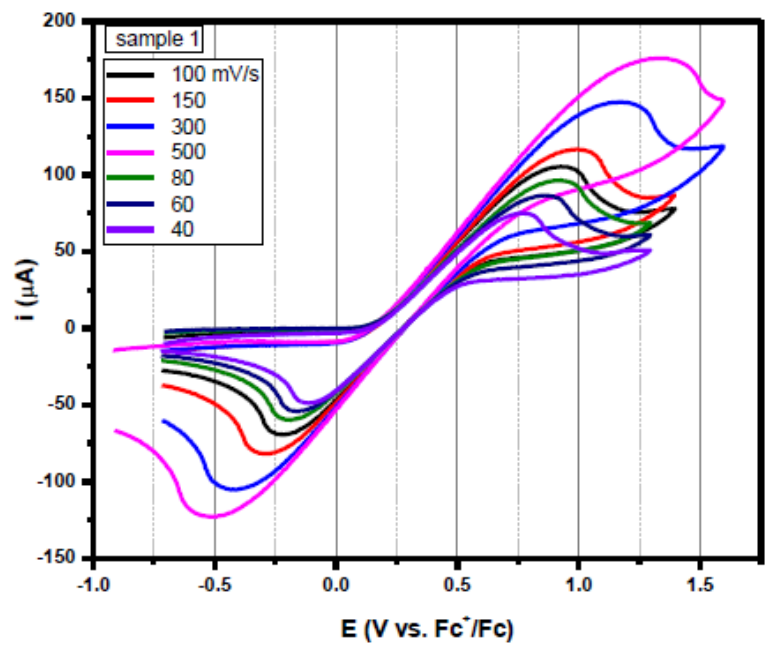

Figure13. Left: Cyclic voltammograms $\left(\mathrm{Fe}^{\mathrm{II}} / \mathrm{Fe} \mathrm{III}^{\mathrm{II}}\right.$ ) of sample 2 in $\mathrm{CHCl}_{3}{ }^{\mathrm{n}} \mathrm{Bu}_{4} \mathrm{NPF}_{6}$, with a Au disk electrode (2 mm in diameter) at different scan rates, as indicated. Right: Randles-Sevcik plots for the anodic $\left(i_{p, a} ;\right.$ black circles) and the cathodic ( $i_{p, c}$; blue squares) part of the wave 
$E_{1 / 2}$ values of the copolymers were more positive than the $E_{1 / 2}$ value of the monomer (15) and they increased as the PEO/PMAEFc ratio in the polymer chain increased. In addition, the oxidation potential $\left(E_{\mathrm{p}, \mathrm{a}}\right)$ moved to more positive values as the MAEFc content increased, while the reduction potential $\left(E_{\mathrm{p}, \mathrm{c}}\right)$ moved in the negative direction, and consequently the peak-to-peak separation $(\Delta E)$ increased from 1,231 to $1,590 \mathrm{mV}$. Those results indicate that the oxidation of the copolymers became more difficult and that the kinetic reversibility of the redox process was diminished. This behavior can be attributed to the slower diffusion and therefore the lower rate of charge transfers in agreement with previous observations $(15,25)$. Although all solutions had the same concentration, the peak current $\left(i_{\mathrm{p}, \mathrm{a}}\right)$ for sample 3 (with the highest MAEFc content) was significantly lower compared to the other two samples and this can be attributed to a combination of slower diffusion coefficients because of larger size and amore incomplete oxidation of the ferrocene moieties within the copolymer.

\section{ConClusions}

Atom transfer radical polymerization (ATRP) techniques were employed for the successful synthesis of redox responsive amphiphilic block copolymers of ethylene oxide, EO, and 2methacryloyloxyethyl ferrocenecarboxylate, MAEFc. Size exclusion chromatography (SEC) and ${ }^{1} \mathrm{H}$ NMR spectroscopy were employed to characterize the samples. The self-assembly behavior of these amphiphilic copolymers was studied in aqueous solutions and in acetonitrile, both selective solvents for the PEO block. Dynamic Light Scattering (DLS) was employed for the study of the association behavior. The formation of supramolecular structures (micelles and micellar aggregates) was revealed by using the CONTIN algorithm. The thermal properties of the block copolymers were investigated by differential scanning calorimetry (DSC) and thermogravimetric analysis (TGA). The electrochemical properties of the copolymers were studied by cyclic voltammetry as well.

\section{REFERENCES}

[1] (a) Wöhlre, D., Pomogailo, A.D. in Metal complexes and metals in macromolecules Wiley-VCH Weinheim, 2003.

[2] (a) Whitell, G.R., Manners, I. (2007) Adv. Mater. 19: 3439-3468.

(b) Abd-El-Aziz, A., S. (2002) Macromol. Rapid. Commun., 23: 995-1031.

(c) Pittman, C., U., Jr., J. (2005) Inorg. Oranomet. Polym. Mater., 15: 33-55.

[3] (a) MacLachlan, M., J., Ginzburg, M., Coombs, N., Coyle, T., W., Raju, N., P., Greedan, J., E., Ozin, G., A., Manners, I. (2000) Science, 287: 1460-1463.

(b) Ma, Y., J., Dong, W., F., Hempenius, M., A., Möhwald, H., Vancso, G., J. (2006) Nat. Mater., 5: 724-729.

(c) Kaifer, A., E. (2007) Eur. J. Inorg. Chem. 32: 5015-5027.

(d) Ornelas, C., Ruiz, J., Belin, C., Astruc, D. (2008) J. Am. Chem. Soc. 131: 590-601.

[4] (a) Aranzaes, J., R., Belin, C., Astruc, D. (2006) Angew Chem. Int. Ed., 45: 132-136.

(b) Ruiz, J., Medel, M., J., R., Daniel, M., C., Blais, J., C., Astruc, D. (2003) Chem. Commun., 464-465.

[5] (a) Péter, M., Lammertink, R., G., H., Hempenius, M., A., Vancso, G., J. (2005) Langmuir, 21: 5115-5123.

(b) Lu, J., Chamberlin, D., Rider, D., A, Liu, M., Z., Manners, I., Russell, T., P. (2006) Nanotechnology, 17: 5792-5797.

[6] (a) Lastella, S., Jung, Y., J., Yang, H., C., Vatjai, R., Ajayan, P., M., Ryu, C., Y., Rider, D., A., Manners, I. (2004) J. Mater. Chem. 14: 1791-1794.

(b) Hinderling, C., Keles, Y., Stockli, T., Knappy, H., E., De los Acros, T., Heinzelmann, H. (2004) Adv. Mater. 16: 876-879.

[7] Amer, W., A., Wang, L., Amin, A., M., Ma, L., Yu, H. (2010) J. Inorg. Organomet. Polym. Mat., 20: 605-615.

[8] Charles, U., Pittman, Jr. (2005) J. Inorg. and Org. Polym. Mat., 15: 33-55.

[9] Manners, I. Synthetic Metal-Containing Polymers, Wiley-VCH,Weinheim 2004.

[10] (a) Chuang, V., P., Gwyther, J., Mickiewicz, R., A., Manners, I., Ross, C., A. (2009) Nano Lett., 9: 4364-4369.

(b) Zhao, D., Ren, B., Liu, S., Liu, X., Tong, Z. (2006) Chem. Commun., 779-781. 
[11] Masson, G., Lough, A., J., Manners, I. (2008) Macromolecules, 41: 539-547.

[12] (a) Gallei, M., Tockner, S., Klein, R., Rehahn, M. (2010) Macromol. Rapid Commun., 31:889896.

(b) Gallei, M., Schmidt, B., V., K., J., Klein, R., Rehahn M. (2009) Macromol. Rapid Commun., 30: 1463-1469.

[13] Feng, C., Shen, Z., Yang, D., Li, Y., Hu, J., Lu, G., Huang, X. (2009) J. Polym. Sci. Part A: Polym Chem, 47:4346-4357.

[14] (a) Hardy, C.G., Ren, L., Tamboue, T.C., Tang, C. (2011) J. Polym. Sci. Part A: Polym. Chem., 49(6): 1409-1420.

(b) Liu, L., Rui, L., Gao, Y., Zhang, W. (2015) Polym. Chem., 6:1817-1829.

[15] Droulia, M., Anastasaki, A., Rokotas, A., Pitsikalis, M., Paraskevopoulou, P. (2011) J. Polym. Sci. Part A: Polym. Chem., 49: 3080-3089.

[16] Krishnan, R., Srinivasan, K., S., V. (2005) J. Appl. Polym. Sci., 97: 989-1000.

[17] (a) Block copolymers. Synthetic strategies, physical properties and applications Hadjichristidis, N., Pispas, S., Floudas, G.A. J. Wiley \& Sons, 2003.

(b) Gohy, J., F., Lohmeijer, B., G., G., Alexeev, A., Wang, X., S., Manners, I., Winnik, M., A., Schubert, U., S. (2004) Chem. Eur. J., 10: 4315 -4323.

(c) Guerin, G., Raez, J., Manners, I., Winnik, M. A. (2005) Macromolecules, 38: 7819-7827.

[18] (a) Abetz, V., Simon, P.F.W. (2005) Adv. Polym. Sci., 189: 125.

(b) Hadjichristidis, N., Iatrou, H., Pitsikalis, M., Pispas, S., Avgeropoulos, A. (2005) Progr. Polym. Sci., 30: 725.

[19] (a) Gohy, J.F. (2005) Adv. Polym. Sci., 190: 65.

(b) Riess, G. (2003) Progr. Polym. Sci., 28: 1107.

(c) Rodrígeuz-Hernádez, J., Chécot, F., Gnanou, Y., Lecommandoux, S. (2005) Progr. Polym. Sci., 30: 691.

[20] (a) Discher, D.E., Eisenberg, (2002) A. Science, 297: 967.

(b) Hamley, I.W. (2003) Nanotechnology, 14: R39.

(c) Chen, D., Jiang, M. (2005) Acc. Chem. Res., 38: 494.

(d) Dwars, T., Paetzold, E., Oehme, G. (2005) Angew. Chem. Int. Ed., 44: 7174.

(e) Kita-Tokarczyk, K., Grumelard, J., Haefele, T., Meier, W. (2005) Polymer, 46: 3540.

[21] (a) Qi, L., Cölfen, H., Antonietti, M. (2001) Nano Lett., 1: 61.

(b) Cohen Stuart, M.A., Hofs, B., Voets, I.K., de Keizer, A. (2005) Curr. Opin. Colloid Inter. Sci., 10: 30 .

[22] (a) Morsbach, J., Elbert, J., Rüttiger, C., Winzen, S., Frey, H., Gallei, M. (2016) Macromolecules, 49: 3406.

(b) Gracia, R., Mecerreyes, D. (2013) Polym. Chem., 4: 2206.

(c) Xiao, Z. P., Cai, Z. H., Liang, H., Lu, J. (2010) J. Mater. Chem., 20: 8375-8381.

(d) Liu, L., Rui, L., Gao, Y., Zhang, W. (2015) Polym. Chem., 6:1817-1829.

[23] Zamurovic, M., Christodoulou, S., Vazaios, A., Iatrou, E., Pitsikalis, M., Hadjichristidis N. (2007) Macromolecules, 40: 5835.

[24] Casado, C. M., Cuadrado, I., Morán, M., Alonso, B., García, B., González, B., Losada, J. (1999) Coord. Chem. Rev., 185: 53-80.

[25] Ren, B., Zhao, D., Liu, S., Liu, X.; Tong, Z. (2007) Macromolecules, 40: 4501-4508. 


\section{SUPPORTING INFORMATION}
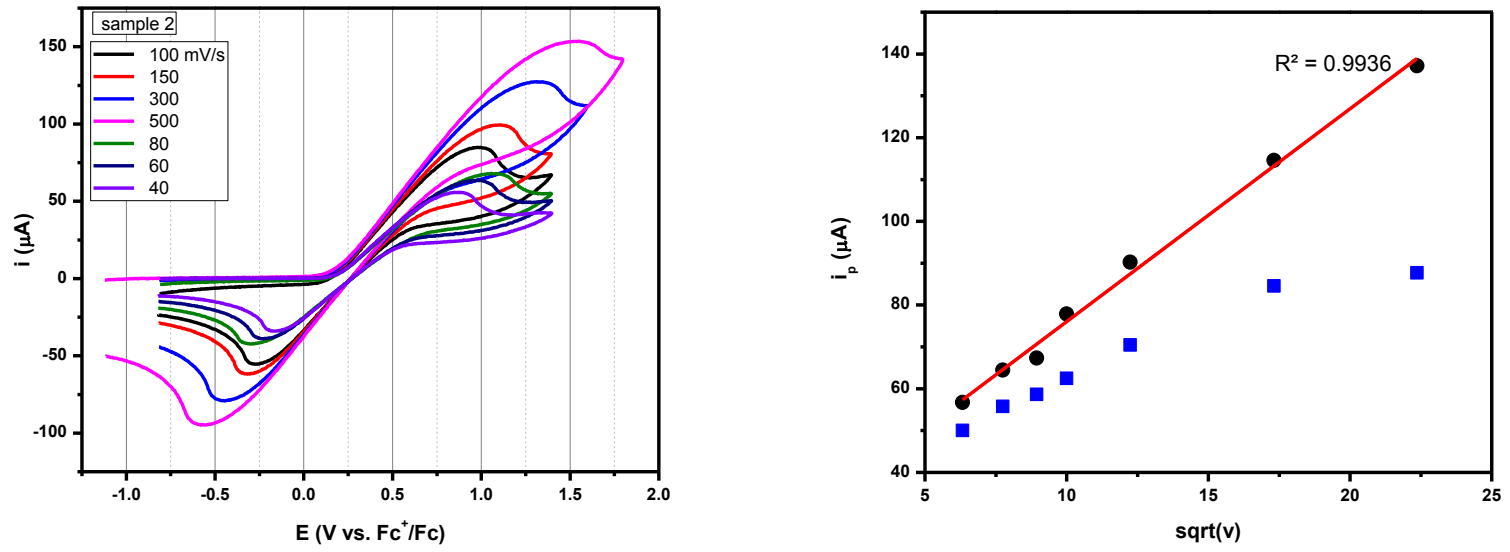

${ }^{1} \mathrm{H}$ NMR spectrum of MAEFc

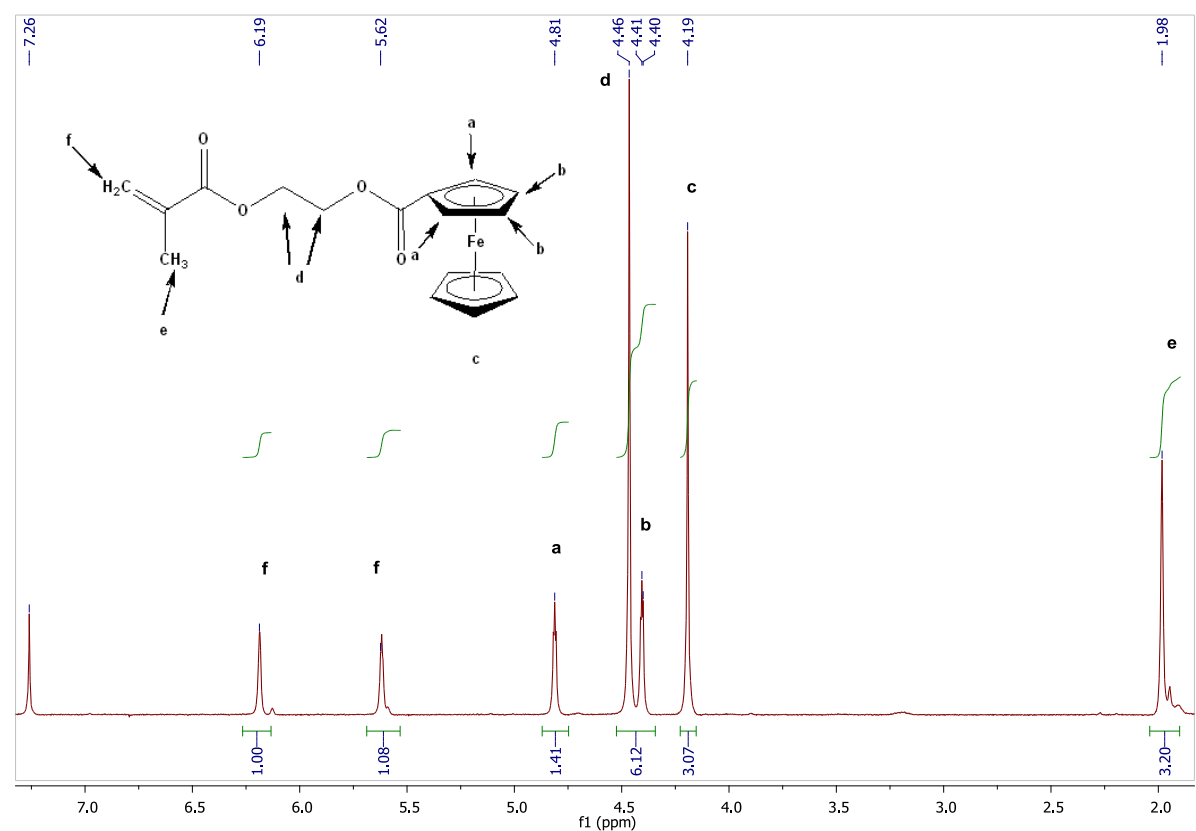

${ }^{1} \mathrm{H}$ NMR spectrum of PEO- $b$-PMAEFc

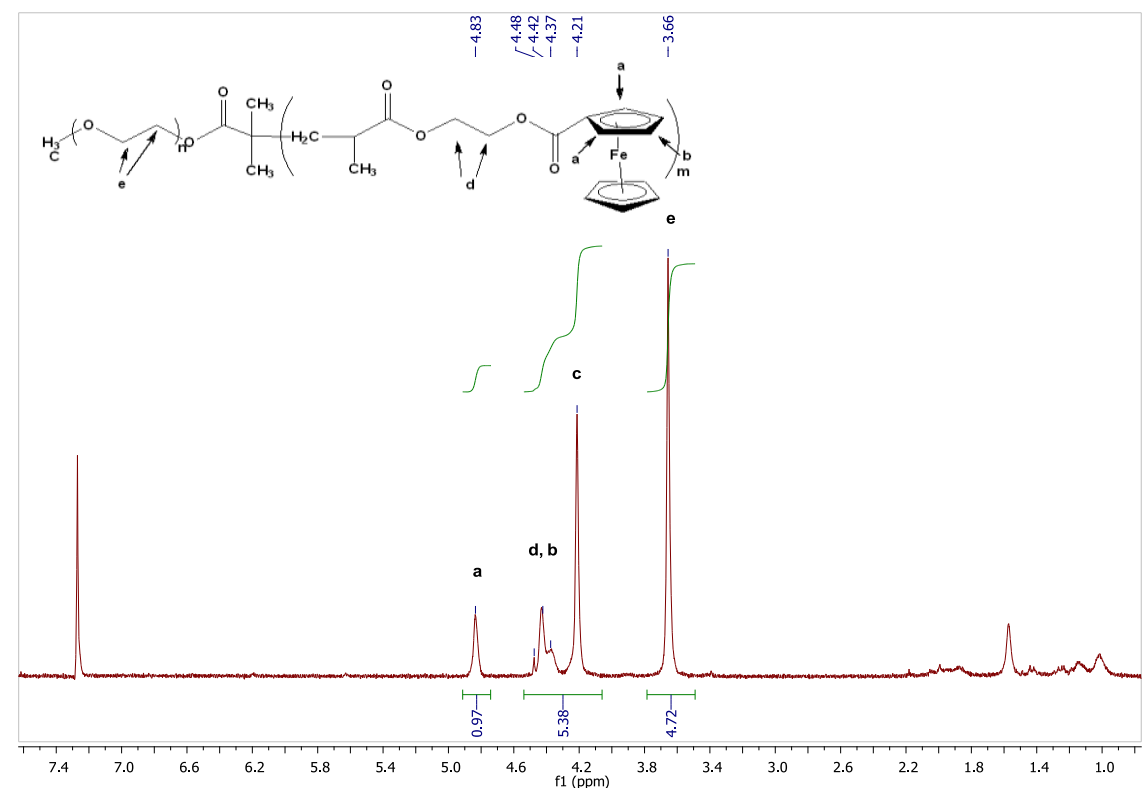

